\title{
Scour prediction offshore and soil erosion testing
}

\section{Richard Whitehouse and John Harris ${ }^{1}$}

${ }^{1}$ HR Wallingford Ltd, Howbery Park, Wallingford, Oxfordshire OX10 8BA, UK

Proceedings of the OMAE2014 - ASME 2014 33rd International Conference on Ocean, Offshore and Arctic Engineering, San Francisco, California, USA, 8-13 June 2014

\section{Abstract}

The analysis of the flow mechanisms causing scour in the marine environment combined with a conceptual model for scour in different seabed soils are applied to demonstrate how erosion testing can be used to support detailed assessments of scour. The important role of scour hazard assessment and scour monitoring in the life-cycle management of offshore assets is also assessed.

Key words: Ocean engineering, Erosion, Testing

\section{Introduction}

Guidance on local scour in the marine environment usually relates to equilibrium scour in uniform granular soils. Scouring is controlled by the balance between the applied forces of the fluid flow, its interaction with the foundation structure and the ability of the soil to resist the applied forces. This paper draws on a conceptual scour model as the basis for consideration of how different soils would be expected to scour.

Offshore renewable energy projects typically require the placement of a great many individual foundations, which are then subject to the full spectrum of environmental loads, and it has become increasingly important to be able to predict scour behaviour at these structures. Data obtained from built projects provide analogue conditions and indicative ranges of scour that might be expected for different water depths, metocean conditions and soil type. Determining the mobility and, hence, the scour potential of fine grained soils is important, since the onset and rate of scour is not known a priori. Erosion characteristics are especially important when a time-varying scour prediction method is to be applied for clay influenced soils over both short-term and long-term scour development. There are many methods for erosion testing which operate on laboratory prepared sediments and also methods for testing sediments collected from the field. This paper classifies the complete range of approaches and discusses the benefits and practical difficulties in carrying out tests, as well as the interpretation of results. This is especially the case when needing to compare results to the Shields diagram.

Conclusions on the role of erosion testing in offshore projects are made as well as the requirement to validate scour prediction through comparison of environmental loads, soil conditions and the resulting scour data. The results provide a basis for illustrating the benefits of including site-specific erosion parameters in engineering studies. 
A framework is presented that allows the complete life-cycle assessment of scour hazard to be made for a given project, from survey, through desk study and detailed analysis, laboratory or field testing of erodibility, and monitoring.

\section{The processes driving scour}

The current-driven flow process around a vertical cylinder has been studied and applied to scour prediction. The development of knowledge on flow processes and scour can be followed in publications by Shen et al. (1969), Baker (1980), Breusers and Raudkivi (1991), Ahmed and Rajaratnam (1998), Melville and Coleman (2000), Roulund (2000), Graf and Istiarto (2002) - and discussion by Babaeyan-Koopaei (2003), and Sumer and Fredsøe (2002). The flow field can be described by the three familiar phases: downflow at the front of the cylinder due to the vertical pressure gradient along the stagnation line; the horseshoe vortex at the junction of the cylinder and the bed; and the wake vortex. These phases are formed during the flat bed stage before scour occurs and continue once the scour has formed (Figure 1). It is useful to characterise the processes in each phase causing erosion.

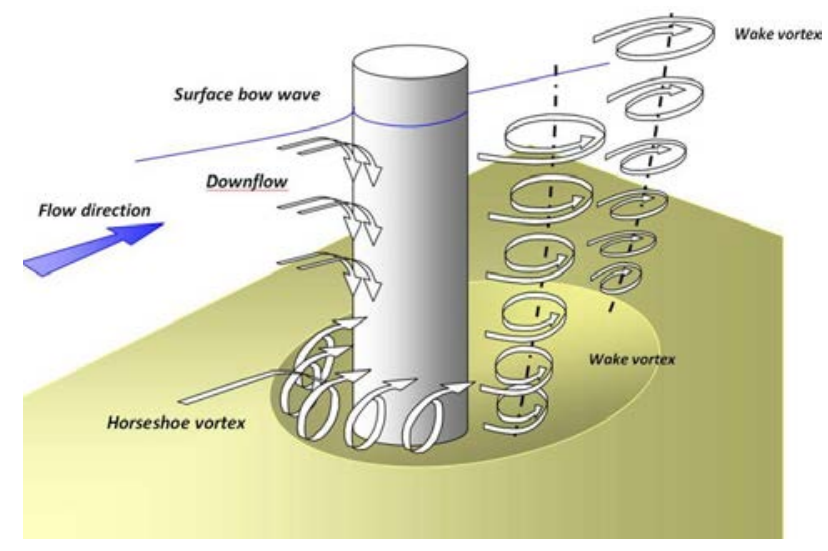

Figure 1 Schematic diagram of the different phases of flow development.

For shallow water conditions, the downflow at the face of the cylinder has a strength that is related to the oncoming flow speed and bed roughness, since a rough bed will steepen the velocity gradient in the approaching boundary layer. The work referred to in the previous paragraph indicates the downflow is in the range 0.25 (Roulund, 2000) to $0.95 \mathrm{U}$ (Ahmed and Rajaratnam, 1998) with other values in between being possible. It is generally concluded the strength of the downflow is increased as the scour develops with the larger values occurring within the scour hole. Breusers and Raudkivi (1991) state the maximum value of the downflow is about $0.8 \mathrm{U}$ and occurs "in the scour hole at about one pier diameter below the bed level." (p.63).

The flow speed around the cylinder is increased locally by a factor of 2 due to flow acceleration although the overall local increase in flow and bed shear stress due to the combined effect of acceleration and the horseshoe vortex at the bed is larger (Whitehouse, 1998). In the wake vortex, horizontal rotating fluid is advected with the ambient flow. In all these zones turbulence needs to be considered, as it will enhance the time-averaged flow and bed shear stress (Whitehouse and Damgaard, 2001; Annandale, 2006; Hoffmans, 2012). Depending on the soil conditions scour may be initiated at the front or at back of the cylinder due to the relative strength of the different flow mechanisms in comparison to the erosion resistance of the soil. Where the scour is in the live-bed condition (sediment mobile everywhere) scour will be initiated at the front face of the pile and it then extends downstream due to the developing phases of flow. In the clearwater 
condition (sediment mobile only locally at the cylinder) scour will be initiated in front of the cylinder and develop downstream, but where the time-averaged shear stress is not much larger than the threshold condition it may be the turbulent fluctuations that drive the erosion. These considerations will apply equally to clay influenced soils and it may be that the scour starts behind the cylinder before developing around to the front side (Briaud et al., 2001).

\section{Conceptual model for scour and life-cycle assessment framework}

Scour provides a controlling process on the bed level at a foundation, reducing embedment depth and altering the structural response. Figure 2 presents a framework to enable a complete life-cycle assessment of scour hazard to be made for any given project, from survey, through prediction, laboratory or field testing of erosion, and monitoring.

From existing offshore wind farm developments, which represent the principal body of collected monitoring data, the range of expected scour for sites with different water depths have been drawn from the field evidence database. The results compare favourably to the conceptual model and provide some limits on the values of scour that might be expected. The sediment mobility is implicit in the results and since not all fine grained soils behave in the same way the role of soil erosion testing is considered. Erosion characteristics are especially important when a time-varying scour prediction method is to be applied in clay influenced soils.

This paper uses a conceptual scour model as the basis for consideration of the erodibility of different soils (Figure 3). The model was originally presented by Whitehouse (2006) and illustrates the idea that deepest scour is generally expected for sand under normal current plus wave conditions, which we will clarify here as being current dominated. Because we expect sand to be already in a mobile state on the continental shelf the scour is expected to develop under live-bed conditions, which provide the largest scour depths. Clearly there will be some natural variation in scour depth under a modulating tidal current. In Figure 3, to the right of sand on the conceptual model lie the larger grade sediments, which are also akin to scour protection materials. These coarser sediments are expected to experience reduced scour depth with increasing sediment size due to having greater resistance to erosion. On the left hand side of the model the scour in stiff clay is expected to be reduced by virtue of the strength of the clay being overconsolidated and scour depth in clay soils will vary widely due to the degree of consolidation. The other three sediment categories have varying scour depth by virtue of the varying make up of the different grade material. The model provides a guide to the degree of scour that can be anticipated, and this is linked to the Folk diagram so that site specific classification of sediment can be linked to the conceptual scour model (Figure 4). The conceptual model takes the Folk type Mud: Gravel: Sand classification of soil types as its starting point.

The evidence offshore of scour holes around monopile foundations, with external diameter $D$, is described in Whitehouse et al. (2010) and Harris et al. (2010a). The controlling effect of hydraulics and sediment properties is clear in this data with scour depths in areas of fast current, shallow water and mobile sandy sediments up to 2D deep and in silt influenced sands and widely graded mixes of sands and gravels as low as 0.1D. This provides some quantification for the 'High' and 'Low' limits on the scour depth axis of the conceptual model. The Scour Management Plan provides a framework for managing the life-cycle assessment of scour hazard. For a specific project scour hazard can be screened (Whitehouse, 1998; 2006) to determine the ultimate scour depth although the rate of scour development is only codified for uniform sands (DNV, 2013). 


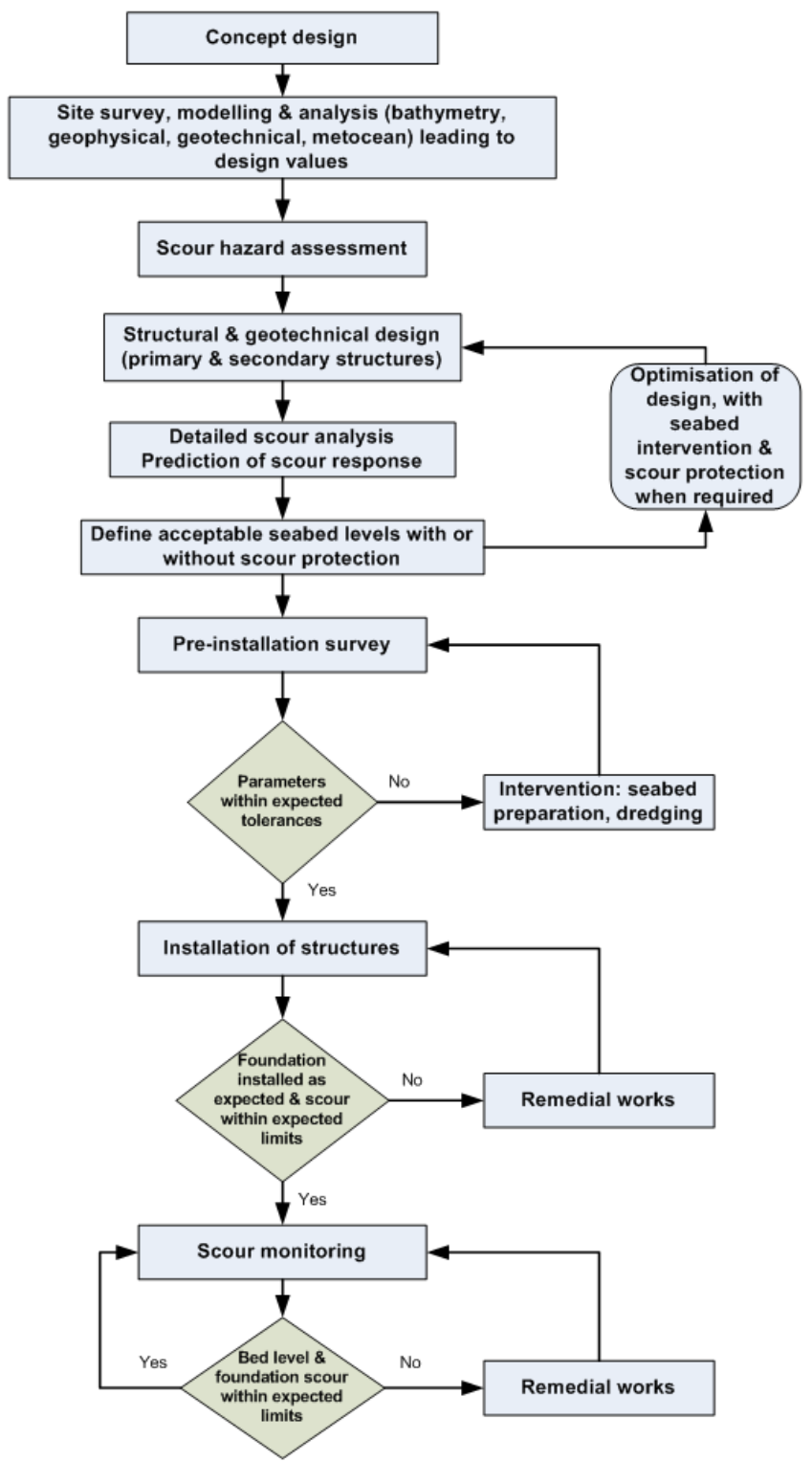

Figure 2 Life-cycle Scour Management Plan

Source: Whitehouse et al., 2011 
Conceptual model of the relative scour depth for different sediments in the marine environmen Normal' current plus wave conditions

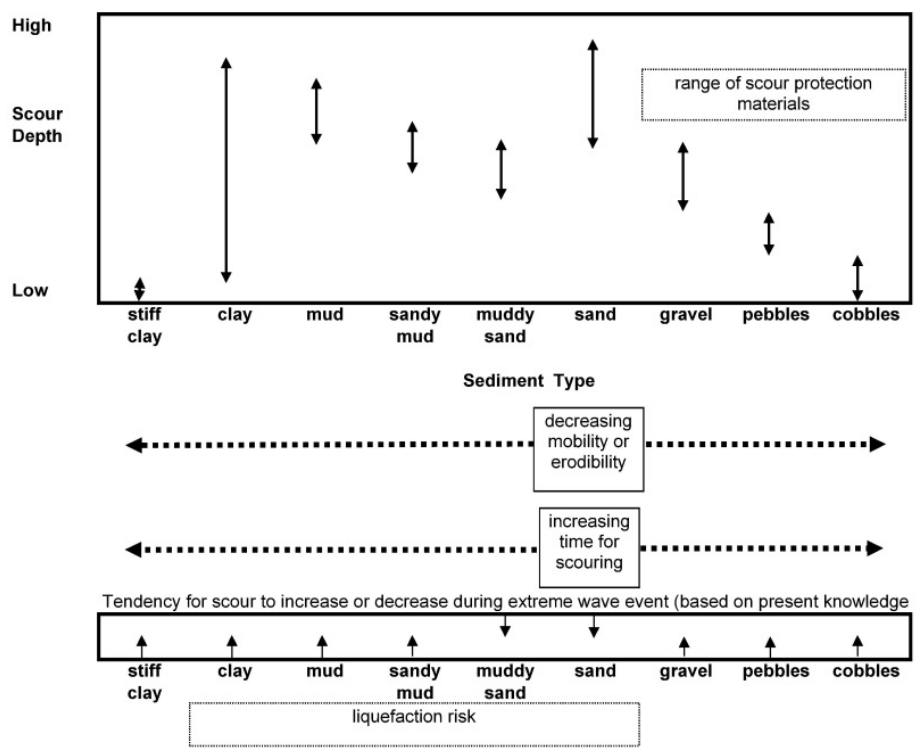

Figure 3 Conceptual model for scour

Source: Whitehouse, 2006

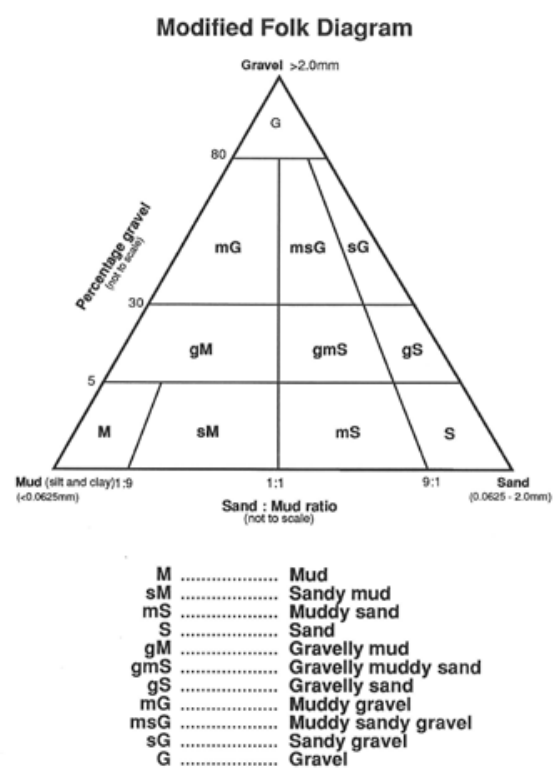

Figure 4 Folk sediment classification diagram

Obviously for detailed engineering design it will be necessary to analyse scour hazard for specific metoceanstructure-soil conditions using appropriate methods (Harris et al., 2010a, 2010b). Whenever possible validation of the methods with field data from existing projects with built structures should be demonstrated. 


\section{Erodibility in scour hazard assessment}

For completion of a scour hazard assessment, the resistance of the seabed soil is required. For sandy sediment the Shields approach can be used as a reasonable guide to erodibility based on the properties of grain size and mineral density.

There are many methods available for erosion testing which operate on laboratory prepared sediments, as well as methods for testing sediments collected from the field. This paper classifies the complete range of approaches and discusses the benefits and practical difficulties in carrying out tests and in the interpretation of results. This is especially the case when needing to compare results to the Shields diagram. Box cores taken from the field and tested in a laboratory flume show how the erosion of natural sediments (in this case marked Clyde and Channel) compare with the Shields curve. The threshold condition for a uniform sand is also marked by way of a calibration value and lies on the curve (Figure 5).

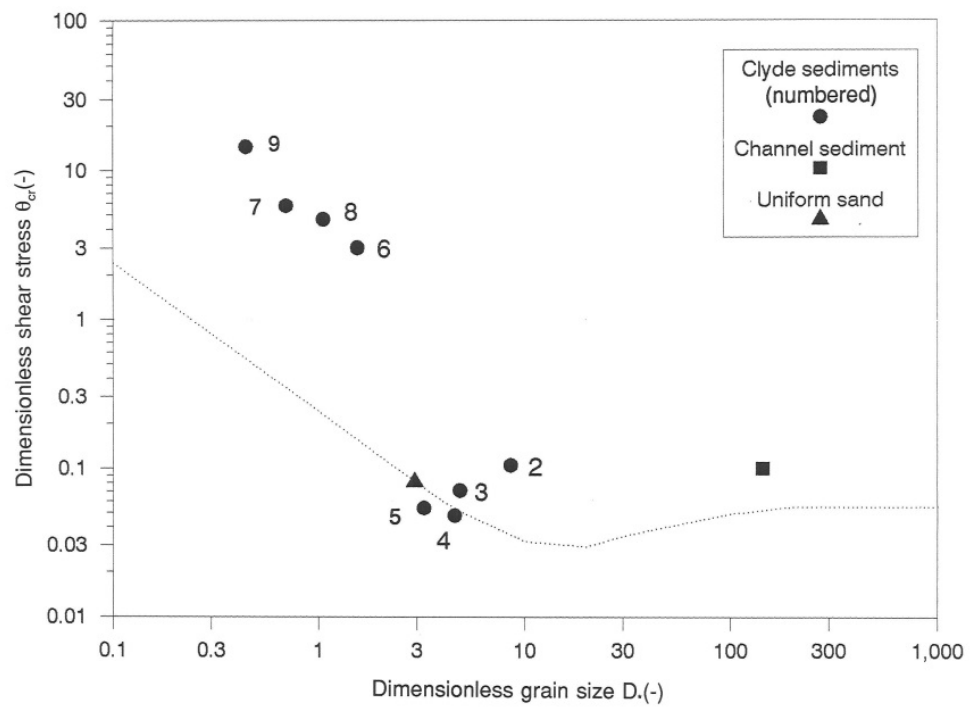

Figure 5 Comparison of site data for threshold of erosion with the Shields curve (dashed line).

Imberger et al. (1982) studied scour around a pile for sand $\left(d_{50}=0.2 \mathrm{~mm}\right)$ and a marine calcareous soil $\left(d_{50}=\right.$ $0.06 \mathrm{~mm}$ ) in the laboratory. "In the case of sand, scour is achieved by the suspension of the material and subsequent slumping". In contrast, for the case of the calcareous soil, it appeared that the eddying in the horseshoe vortex resulted in local scour, "which deepened at first and then broadened to form a sheet like scour depression. The failure of the soil was much more [by] lateral or horizontal scouring by the fluid as it swept past the near vertical sediment walls. There was very little evidence of the sediment slumping at any stage of the scour process" (p. 1553). Despite the difference in processes for the two soils the sediment data and the sand data showed the same correlation between $S / D$ (where $S$ is the scour depth and $D$ is the pile diameter) and the flow strength parameter $u_{*} / u_{*_{c}}$ (where $u_{*}$ is the shear velocity and $u_{*_{c}}$ is the shear velocity at which bed motion is initiated over an unobstructed bed). "This implies that, even though the mechanisms are different, it is the turbulent kinetic energy that is ultimately responsible for the scour. Similarly it is the single parameter $u_{*_{c}}$ which determines the resistance of the soil to scour." (p. 1553). The horseshoe vortex grows as the scour hole grows, gaining "size and strength as additional fluid attains a downward component and the strength of the downflow increases." (р. 1553). 
Another approach is to take a core from the seabed and test that in a laboratory procedure. This method has been used in different flume type devices with sediment cores introduced into the bed of an enclosed flow conduit for river (Briaud et al., 2001) and ocean sediments (Jepsen et al., 2004). The erosion rate is measured directly through height of core eroded per unit time (converted to mass with knowledge of core density) and a relationship between applied flow speed or shear stress and erosion rate is obtained. The threshold condition can be obtained by extrapolation of the results to zero loss.

The Erosion Function Apparatus (EFA) (Briaud et al., 2001) has been used to assess erosion risk for the Adriatic LNG gravity base foundation (Chen et al., 2011). The capacity of the clay substrate to resist erosion needed to be assessed as the foundation skirt penetrated into that layer to retain the $0.4 \mathrm{~m}$ deep silty sand surficial layer. The surficial layer was expected to erode easily, which would leave the clay exposed to near bottom velocities. The EFA results showed the critical flow velocity for the clay was $0.5 \mathrm{~m} / \mathrm{s}$ and that storm waves and currents would exceed this value even with $1 \mathrm{~m}$ of scour. Therefore, based on site specific erosion tests the erosion risk was confirmed, and a clearly justifiable decision was taken to deploy scour protection to prevent undermining of the foundation skirt.

Alternatively, subsea flumes can be deployed from a survey platform to derive surface layer erosion thresholds and erosion rates at multiple locations (Amos et al., 2010). The only limitation with these for scour testing is that they provide data only on shear-induced erosion of the surface layer. For scour studies it would be possible in principle to devise an actuator driven method to introduce a cylinder into the test section of a subsea flume. This would provide the same form of data obtained by Imberger et al. (1982) but directly at the seafloor.

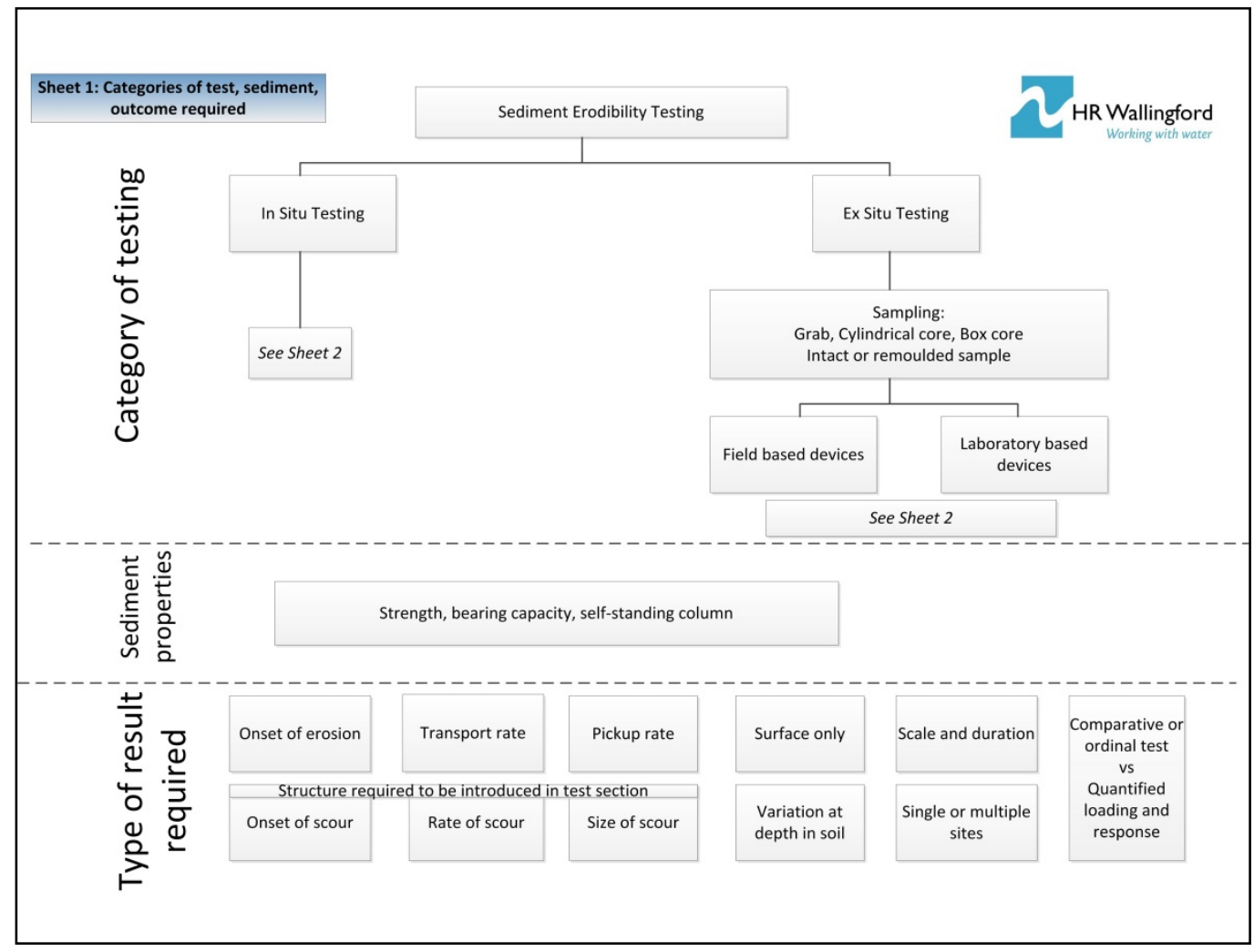

Figure 6 Erosion test procedure decision chart. 


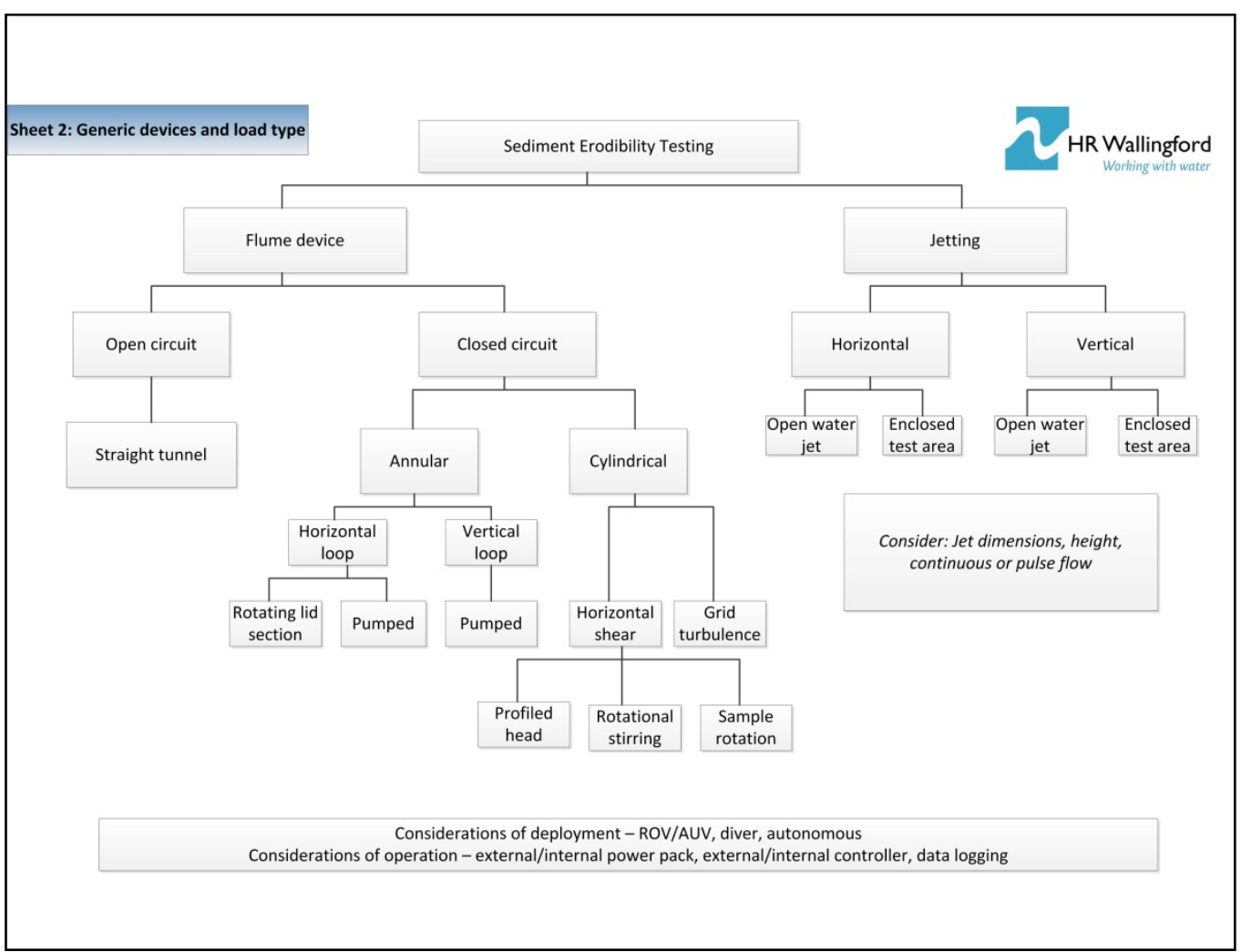

Figure 7 Generic typology of erosion testing devices

Clearly some devices produce results in terms of a flow speed and others in terms of a shear stress, obtained by calibration, and the interpretation of erosion results and application to studies requires a consistent matching of hydraulic roughness and boundary layer parameters.

The latest edition of HEC-18 (FHWA, 2012) recognises the importance of including an assessment of erodibility in bridge scour studies. A graphical relationship between erosion rate and velocity is provided with erodbility categorised in terms of soil parameters and the Unified Soil Classification System. This adopts a similar approach to the conceptual model presented in this paper.

The document goes on to state that "For advanced studies and when economy of the project warrants, it is preferable to test the soil in an appropriate erosion testing device." (p.4.11). The available devices are categorised as Piston-Type [a sample or core is exposed to flowing water in a small flume and loss of mass per unit time measured], Rotating-Type [a core is rotated in a fluid filled annular space and loss of mass per unit time measured] and Submerged-Jet [the depth of scour below the jet is measured].

The diagrams in Figure 6 and 7 provide a logical typology for erosion equipment which can be used to inform discussions as to the most appropriate test procedure for hydraulic erosion in many different situations. Laboratory scour tests can be classified on Figure 6 as the methods where a structure such as a pile is introduced into the test section. 


\section{Matching scour testing to scour processes}

The first step is to decide whether in situ or ex situ tests are most suitable and whether for sediment samples obtained the tests will be carried out in the field or laboratory. The sediment properties need to be assessed if a device is to be placed on the sediment surface to ensure there is sufficient support for the device on the soil. Next the type of result required should be determined and once a test outcome is agreed upon the most relevant type of device can be selected.

We consider that the erosion testing devices can be matched to the different phases of the scour process around the foundation. This thinking is informed by soil mechanics where, for example, to analyse the stability of a gravity wall in overturning about the toe and sliding at the base, different test procedures can be applied to soil samples to parameterise shear, compression and extension (Barnes, 1995). In the same way we can consider the three phases of the flow process around the foundation as creating different hydraulic regimes which are amenable to testing using different devices. There is then the question as to whether the tests are performed in situ or ex situ. A sediment core returned to the survey vessel for testing provides as near to an in situ test as will be possible without an underwater test carried out using a marinised device.

For the downflow impacting on the bed in front of the pile there is analogy to a vertical jet, for the horseshoe vortex horizontal shear flow and in the wake vortex rotational motion. It is possible to select devices that match these criteria from the array of generic device types in Figure 7. The vertical jetting is perhaps the most straight forward to achieve, as it can use a fixed geometry nozzle arrangement above a sample. The horizontal shear can be generated using a jet, which may have some similarity to the rotating horseshoe vortex passing across the bed, but a more controlled situation can be achieved using an open or closed circuit flume which draws water at appropriate and increasing shear rates across the sediment surface to induce erosion. The onset of erosion can be determined by measuring the increase in sediment concentration in the water flow within the device. The wake vortex is highly turbulent and to simulate erosion in this region of the bed a cylindrical device producing a rotational flow or oscillating grid turbulence could be appropriate.

Taking an approach flow speed of 0.5 and $1 \mathrm{~m} / \mathrm{s}$ and considering the downflow discussed earlier in the paper, we arrive at downflow speeds in the range 0.1 to $0.8 \mathrm{~m} / \mathrm{s}$. Next an equivalent diameter of jet feeding into the horseshoe vortex between the pile wall and the vortex core is estimated. Sumer and Fredsøe (2002) show from experimental data that the separation distance for the flow boundary layer occurs about $0.6 D$ in front of the pile and assuming the downflow feeds half the vortex we have a flow tube extending $0.3 D$ from the pipe wall. This looks plausible compared with the flow visualization results of Babaeyan-Koopaei (2003) and results from Ahmed and Rajaratnam (1998) and Roulund (2000). The length of bed that is impacted either side of the stagnation line is less easily determined, but based on the numerical work of Roulund we estimate $0.1 D$ either side. Therefore we arrive at a jet area of $0.06 D^{2}$. For a $5 \mathrm{~m}$ diameter pile the bed area impacted is $1.5 \mathrm{~m}^{2}$. The discharge, $Q$, of water in the downflow is hence in the range 0.15 to $1.2 \mathrm{~m}^{3} / \mathrm{s}$. In a vertical jet the total kinetic energy issuing from the nozzle can be estimated from the product of flow discharge and jet speed, $U_{o}$, as proportional to $Q U_{0}{ }^{2}$ (Whitehouse, 1998) thereby equating to $0.8 \mathrm{~J}$ to $394 \mathrm{~J}$. These values can be as high as the values associated with small diameter high speed jets which are associated with jet cutting technology for cable burial (Figure 8).

This provides some direction on the scaling of an appropriate test rig to simulate the energy of the downflow. To assess the erosive potential of the downflow segments of sediment core from different vertical positions within the bed can be tested to determine their susceptibility to erosion down to a depth equivalent to $D$, which, as mentioned earlier, is the depth of scour hole for which the downflow is supposed to be strongest. 


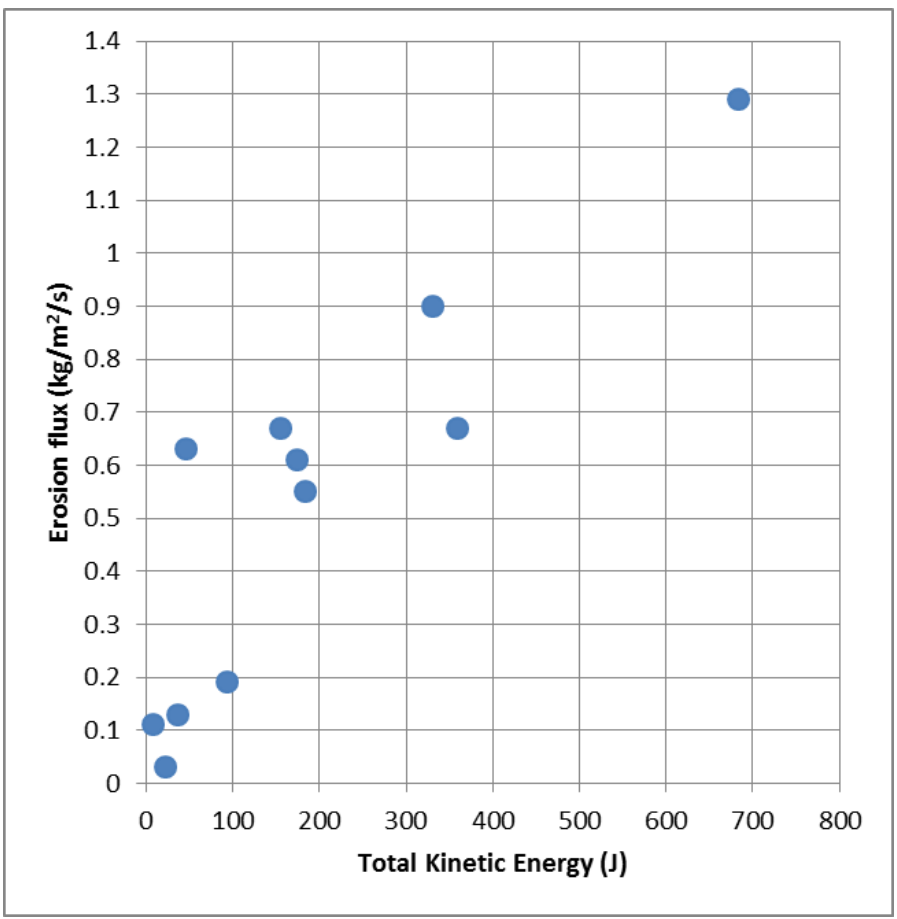

Figure 8 Correlation between erosion flux from a submerged vertical water jet test and the total kinetic energy issuing from the nozzle.

Regarding the shear flow around the pile wall, Roulund (2000) calculated that the maximum bed shear stress occurs between $45^{\circ}-70^{\circ}$. Furthermore, Unger and Hager (2007) reported that scour starts at $75^{\circ}$ from the stagnation line in the oncoming flow. The maximum values of shear enhancement, $M$, due to the horseshoe vortex tube occur within a distance of $0.1 D$ of the pile wall (Whitehouse, 1998; Sumer and Fredsøe, 2002); i.e. the local value of bed shear stress is $M$ times larger than the open seabed value under the same conditions. The absolute value of $M$ typically varies in the range 4 to 10 , but may be larger (Whitehouse, 1998). Taking the representative condition of an ambient flow of $1 \mathrm{~m} / \mathrm{s}$ in $20 \mathrm{~m}$ of water with a hydraulically rough seabed the time-averaged bed shear stress is of order $1 \mathrm{~N} / \mathrm{m}^{2}$. So for a $5 \mathrm{~m}$ diameter pile foundation we arrive at an estimate for the magnitude of applied shear that exists over a distance of about $0.5 \mathrm{~m}$ from the foundation wall as being in the range 4 to $10 \mathrm{~N} / \mathrm{m}^{2}$. Again this provides a direction on the requirements for a test procedure. The area being exposed to shear in the test can be scaled down providing it is still representative of the sediment fabric. Core samples can be tested, using slices from different depths within the bed down to the required depth. The tests will yield the threshold for erosion value and an estimate of erosion rate for a range of applied values of bed shear stress. These values provide important site specific parameters for detailed scour studies.

To obtain specific estimates, Computational Fluid Dynamics (CFD) methods can be used to simulate the driving force for scour around the foundation and yield more detailed information on the locally applied bed shear stress and turbulence levels. The CFD model will require careful selection to ensure it is capable of representing the geometry of the problem and the important processes within the water column and at the seabed (e.g. time-averaged and turbulent quantities and oscillatory waves) and interactions with the foundation structure. Driving the model with appropriate boundary conditions and validating its performance with data will reduce uncertainties in the approximations of the model. Alternatively, hydraulic modelling of the structure in the laboratory will yield specific estimates of the local flow parameters which can be scaled 
up to the field. There is often a lot of insight and reduction in uncertainty to be gained from a combined numerical and laboratory approach.

An example of site specific erosion threshold data from laboratory flume tests on box cores and SedErode (Mitchener et al., 1996) tests in situ for three different sites (Figure 9) show the type of results that can be obtained. Given the sediments are all cohesive and grain size alone is not the controlling factor on erodibility, the data is plotted as a function of dry density as a proxy for sediment strength.

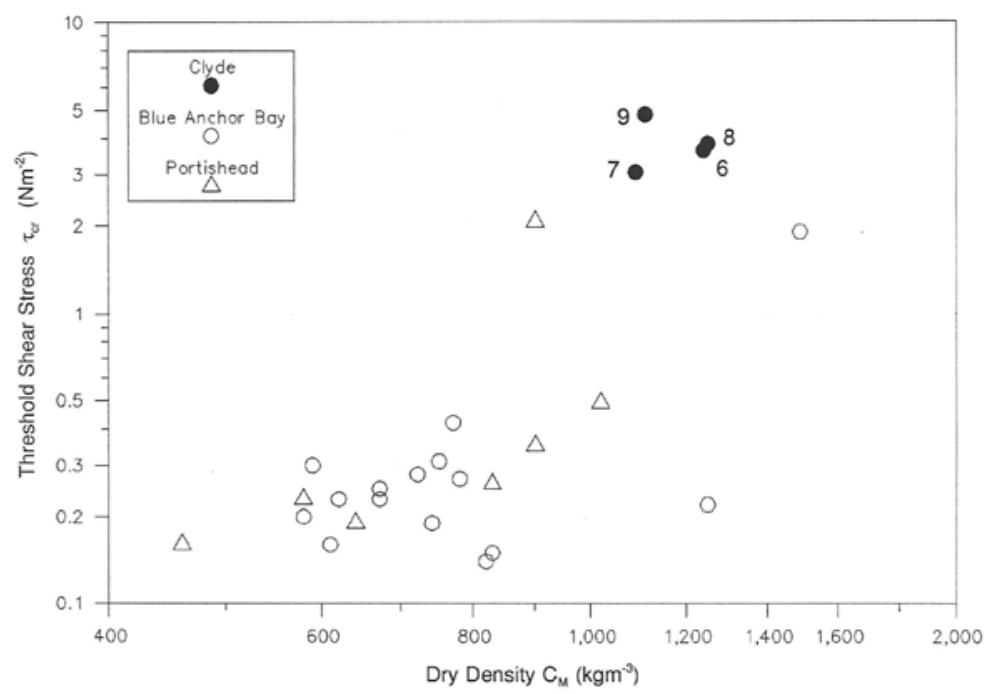

Figure 9 Example relationship between erosion threshold shear stress and sediment density.

\section{Monitoring scour for asset management}

Bed level and scour monitoring during foundation installation and operation of offshore renewable energy projects is often included as a standard requirement within their marine environmental consents licence, and is also an important feedback to the validation of the scour assumption in the engineering design. During engineering design, embedment depths will have been specified for the foundation, and hence pre-specified levels for intervention can also be specified. Scour development within sands in the short-term, driven by tidal cycle modulation and wave events, as well as progressive longer-term development can all be picked up by monitoring.

For clay influenced soils, progressive erosion and extreme event driven erosion can be picked up. Bed level and scour depth can be obtained as spot depths by divers using hand held fathometers, by AUV or ROV mounted sonars, vessel mounted MBES, or fixed bottom frame or foundation mounted sector scanning sonar, single or multiple beam. The choice of monitoring equipment should be dictated by the functional requirements of the project. Price and power constraints for permanent foundation mounted systems need to be considered, as well as the need to integrate such monitoring into the SCADA system, or install a separate telemetry system. 


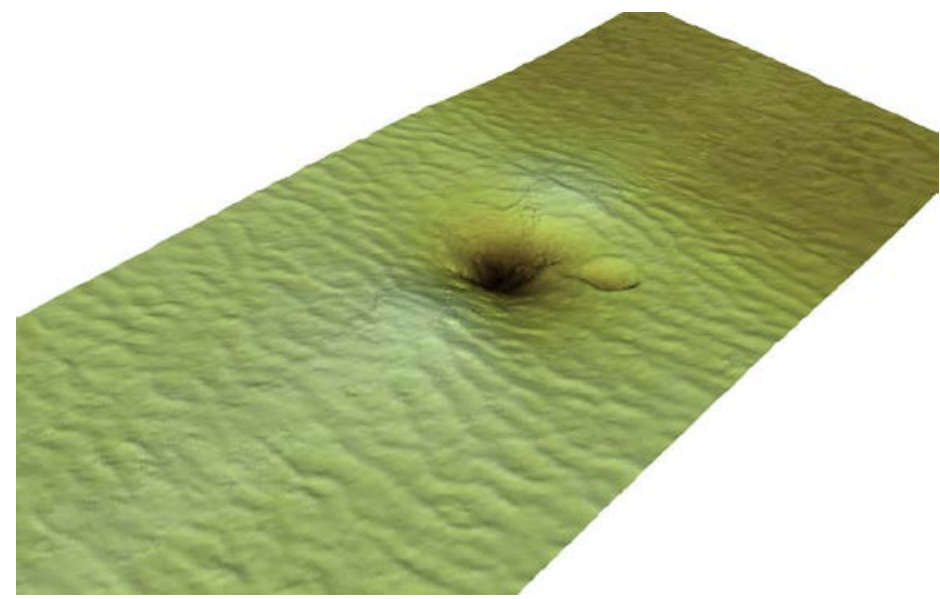

Figure 10 Wind turbine foundation 3D surface contour scour image - monopile located at centre of pit, Princess Amalia Wind Farm

Data source courtesy Van Oord Dredging and Marine Contractors BV - COWRIE, 2010

The vast majority of the scour data already collected is through MBES surveys plotted on a (for example) $100-200 \mathrm{~m}$ square box centered on the foundation. This enables inspection of the scour formation directly around the foundation in context of the local seabed level and the detail of any features such as bedforms (Figure 10).

Sector scanning sonar data was presented by Dixen et al. (2012) for the Gunfleet offshore wind farm. This utilised two Imagenex 881 sonars installed on the up-and-down tide axes of the foundation. A similar sonar configuration has been designed by Kongsberg using their Mesotech Dual Axis Sonar.

The four beam Nortek system (Figure 11) measures water depth at radiating points from the pile face enabling scour depths to be determined near to the bottom of a scour hole in real-time for live bed and deep scour situations. It would also show the situation in progressive scour in the clearwater case where rate effects are not well understood. In the tidal case, care needs to be taken in aligning the device(s) to monitor along the principal tidal axis to take account of the strongest current direction or wave-current sector..

The benefit of these systems is that they can be retro-fitted for a long period of time on pre-installed foundations and provide time-series data (e.g. at 30 minute) intervals simultaneously with metocean measurements. The Nortek scour monitor provides continuous information on bed levels near the foundation to compare with pre-set intervention levels. The only issue with retro-fitting is that the initial scour development may have taken place, and in areas where the scour hole is already large (Figure 12), it has a certain resilience to change. The field data of Dixen et al. (2012) was measured around a turbine foundation that had been in place for 1.5 years and hence the scour hole was well formed at $7.5 \mathrm{~m}$ depth and had a top width of $30 \mathrm{~m}$ or more. Nonetheless, the scour hole deepened by about $0.5 \mathrm{~m}$ over a further period of 6 months after measurements commenced and top width and, hence, scour volume was shown to be increasing progressively at this site.

Given the dynamic processes acting in the scour hole, including sediment avalanching within the scour hole (Harris et al., 2013) and time-varying scour depth due to variable wave-current forcing (Harris et al., 2010b), the devices can be used to monitor the slope angles within the scour hole and record any periodic instability caused by flow slides and shear failure. 


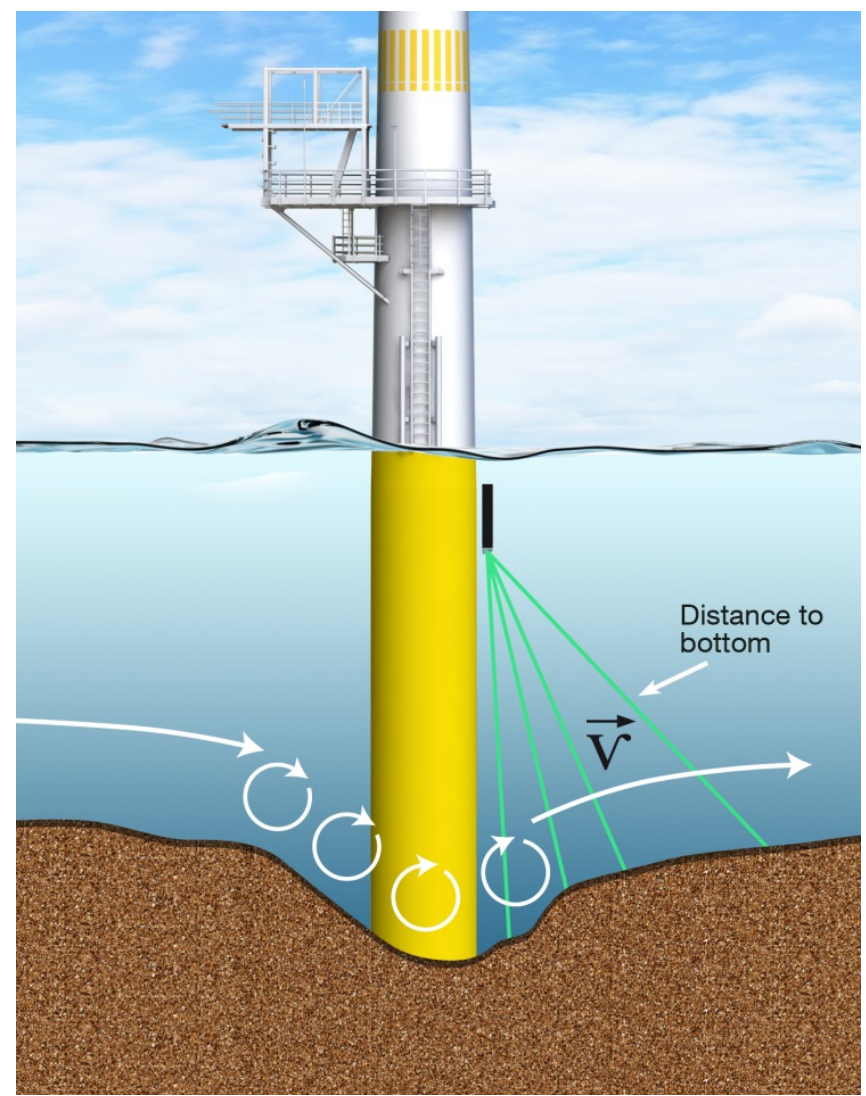

Figure 11 Example scour monitor installation

Graphic courtesy of Nortek UK Ltd - Lind and Whitehouse, 2012

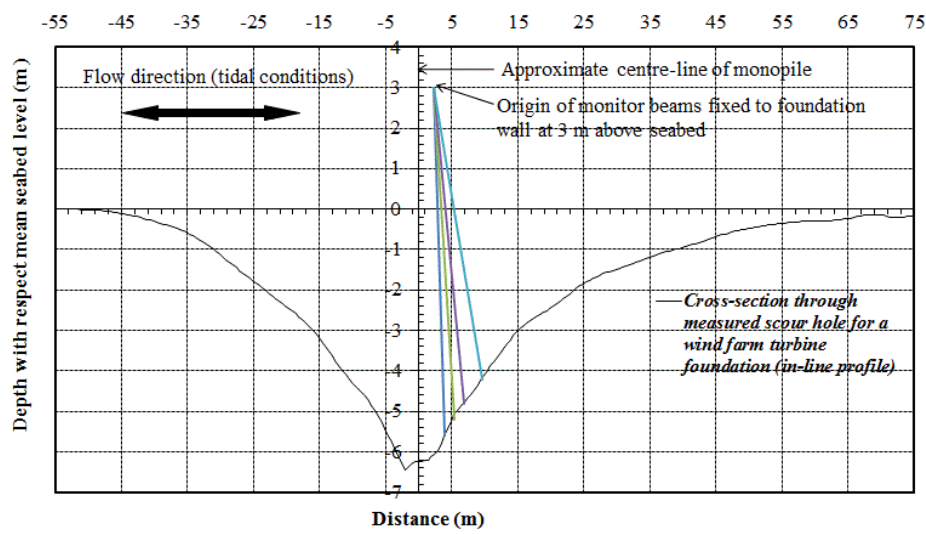

Figure 12 Scour hole cross section measured in the field illustrating the use of the monitor in Figure 11 (beam angles of $10^{\circ}, 20^{\circ}, 30^{\circ}$ and $45^{\circ}$ )

More experience of deploying these systems and analysis of the datasets from them will increase the validation of scour depth variation and extent with time during calm tidal dominated conditions and extreme storm loading. The phasing of scour formation with storm loading is potentially important as the relative strengths of scour and backfill processes in waves and currents need to be better understood (Harris et al., 2010b). 


\section{Conclusions}

Assessment of scour hazard in the marine environment can be delivered through the careful analysis of data on flow, foundation structure and soil characteristics. Scour around a foundation reduces the embedment depth and can be predicted using a range of existing methods. The predicted values inform the life-cycle management of foundations from feasibility to operational stages of a project. The level of the scour analysis depends on the risk of scour to the project and could encompass application of desk study methods drawing on the conceptual scour model and Computational Fluid Dynamics (CFD), or laboratory testing. Whilst CFD methods can be applied at laboratory scale to help interpret test results or at field scale to provide information on scour driving forces, the method requires careful selection to ensure its basis of validity and applicability to the problem in question. When required the uncertainties in CFD can be reduced through comparison with validation data. For critical projects bespoke testing of field samples for their erodibility might be employed to good effect to reduce uncertainty in characterization of the erosion response. To help in selection of methods the variety of erosion testing procedures have been categorized, and examples of the results and their application described. The matching of the flow processes causing scour to the type of erosion testing procedure has also been analysed.

Monitoring fits within the life-cycle assessment and provides valuable data to check the reduction in embedment depth due to scour to ensure that it is within expected limits. This would usually be carried out at periodic intervals as part of the operations and maintenance programme. The value of real-time monitoring of scour levels is assessed as this will provide a more detailed and continuous record of how scour develops in the long-term and responds over shorter time periods to current variation and storm events. The real-time monitoring will highlight the occurrence of instability of scour slopes in sand sediments, and the long-term development of scour in silt and clay dominated sediments where scour does not develop continuously but in response to extreme events.

\section{Acknowledgments}

The paper forms part of the output of the Scour Research Programme of HR Wallingford.

\section{References}

Ahmed, F. and Rajaratnam, N. (1998). Flow around bridge piers. Journal of Hydraulic Engineering, 124 (3), $288-300$. Annandale, G. (2006). Scour Technology. McGraw-Hill.

Amos, C.L., Umgiesser, G., Ferrarin, C., Thompson, C.E.L., Whitehouse, R.J.S., Sutherland, T.F. and Bergamasco, A. (2010). The erosion rates of cohesive sediments in Venice lagoon, Italy. Continental Shelf Research, 30, 859-870. doi: 10.1016/j.csr.2009.12.001.

Babaeyan-Koopaei (2003). Discussion. Flow pattern in the scour hole around a cylinder by Graf and Istiarto (2002). Journal of Hydraulic Research, 41, 443-446.

Baker, C.J. (1980). The turbulent horseshoe vortex. Journal of Wind Engineering and Industrial Aerodynamics, 6, 9-23. Barnes, G.E. (1995). Soil Mechanics. Principles and Practice. Macmillian.

Breusers, H.N.C. and Raudkivi, A.J. (1991). Scouring. IAHR Hydraulic Structures Design Manual, 2, A. A. Balkema, Rotterdam, vii + 143 pp. 
Briaud, J.-L., Ting, F.C.K., Chen, H.C., Cao, Y., Han, S.W. and Kwak, K.W. (2001). Erosion function apparatus for scour rate predictions. Journal of Geotechnical and Geoenvironmental Engineering, 127, 105-113.

Chen, Z., Hurdle, D., Kram, N., Lomónaco, P. and Cornett, A. (2011). Design and testing of scour protection for Adriatic LNG GBS. Paper 49385 Proceedings of the ASME 2011 30th International Conference on Ocean, Offshore and Arctic Engineering, OMAE2011, June 19-24, 2011, Rotterdam, The Netherlands.

COWRIE (2010). A Further Review of Sediment Monitoring Data. Final Report prepared by ABPmer Ltd, HR Wallingford Ltd and CEFAS for the Research Advisory Group, Project Ref. ScourSed-09, March, 115 p.

Dixen, F.H., Dixen, M., Pedersen, J. and Dahl, J.F. (2012). Scour development around offshore wind turbine foundation: Field measurement and analysis. Proceedings ICSE6 Paris, August 27-31, 2012. Paper 202, 1441-1447.

DNV. (2013). Design of Offshore Wind Turbine Structures, Offshore Standard DNV-OS-J101, 214 pp. January 2013.

FHWA. (2012). Evaluating scour at bridges. Hydraulic Engineering Circular No. 18, Publication No. FHWA-HIF-12-003, April 2012.

Graf, W.H. and Istiarto, I. (2002). Flow pattern in the scour hole around a cylinder. Journal of Hydraulic Research, 40 (1), 13-20.

Harris, J.M., Whitehouse, R.J.S. and Sutherland, J. (2010a). Scour assessment in complex marine soils - an evaluation through case examples. In: Proc. of the fifth International Conf. on Scour and Erosion, (eds.) Burns, S.E., Bhatia, S.K., Avila, C.M.C. and Hunt, B.E., Nov. 7 - 10, San Francisco, California, USA, Geotechnical Special Publication no. 210, ASCE, $450-459$.

Harris, J.M., Whitehouse, R.J.S. and Benson, T. (2010b). The time evolution of scour around offshore structures. Proceedings of the Institution of Civil Engineers, Maritime Engineering, 163, March, Issue MA1, $3-17$.

Harris, J.M., Whitehouse, R.J.S., Porter, K. and Simons, R.R. (2013). Scour development through time - modelling scour in layered soils. Paper 10720 Proceedings of the ASME 2013 32nd International Conference on Ocean, Offshore and Arctic Engineering, OMAE2013, June 9-14, 2013, Nantes, France.

Hoffmans, G.J.C.M. (2012). The influence of turbulence on soil erosion. Eburon.

Mitchener, H.J., Whitehouse, R.J.S., Soulsby, R.L. and Lawford, V.A. (1996). Development of SedErode - Instrument for In-Situ mud erosion measurements. Report TR17, HR Wallingford, 17 pp (+tables and figures).

Imberger, J., Alach, D. and Schepis, J. (1982). Scour around circular cylinder in deep water. Proc. 18th Int. Conf. Coastal Engng., Vol 2, 1522-1554, ASCE.

Jepsen, R., Roberts, J. and Gailani, J. (2004). Erosion measurements in linear, oscillatory, and combined oscillatory and linear flow regimes. Journal of Coastal Research: Volume 20 (4), 1096 - 1101.

Lind, R.A. and Whitehouse, R.J.S. (2012). The power of scour. Oilfield Technology, 05 (06), August 2012, 63-67.

Melville, B.W. and Coleman, S.E. (2000). Bridge Scour. Water Resources Publications, LLC, Colorado, USA, 550 pp.

Roulund, A. (2000). Three-dimensional numerical modelling of flow around a bottom-mounted pile and its application to scour. PhD Thesis. Series Paper 70 ISVA, Technical University of Denmark.

Shen, H.W., Schneider, V.R. and Karaki, S. (1969). Local scour around bridge piers. Journal of the Hydraulics Division, Proceedings ASCE, 95 (HY6), 1919-1940.

Sumer, B.M. and Fredsøe, J. (2002). The Mechanics of Scour in the Marine Environment. Advanced Series on Ocean Engng., Vol. 17, World Scientific, Singapore. xiii + 536 pp.

Unger, J. and Hager, W.H. (2007). Down-flow and horseshoe vortex characteristics of sediment embedded bridge piers. Experiments in Fluids, 42, 1-49.

Whitehouse, R.J.S (1998). Scour at marine structures: A manual for practical applications. Thomas Telford, London, $198 \mathrm{pp}$. 
Whitehouse, R. (2006). Scour at coastal structures (Invited lecture). Proceedings Third International Conference on Scour and Erosion, November 1-3, pp. 52-59, (c) CURNET, Gouda, The Netherlands [CD-ROM].

Whitehouse R.J.S. and Damgaard J.S. (2001). Assessing bed stability at coastal structures with external turbulence. Proceedings Coastal Engineering 2000, Sydney, ed. B L Edge, 3008 - 3020. ASCE.

Whitehouse, R.J.S., Harris, J.M., Sutherland, J. and Rees, J. (2010). The nature of scour development and scour protection at offshore windfarm foundations. Mar. Pollut. Bull., doi:10.1016/j.marpolbul.2010.09.007.

Whitehouse, R.J.S., Sutherland, J. and Harris, J.M. (2011). Evaluating scour at marine gravity foundations. Maritime Engineering, 164 Issue MA4, 143-157. Proceedings of the Institution of Civil Engineers doi:

10.1680/maen.2011.164.4.143. 